TAO, Vol.4, No.4, 339-350, December 1993

\title{
Application of CSAMT Method for Gold-Copper Deposits, Chinkuashih Area, Northern Taiwan
}

\author{
CHOW-SON CHEN 1 \\ (Manuscript received 20 September 1993, in final form 22 November 1993)
}

\begin{abstract}
This paper deals with the Controlled Source Audiofrequency Magneotelluric method (CSAMT) applied to gold-copper deposits, in the Chinkuashih area, northern Taiwan. This is the very first time CSAMT has been used for precious metals exploration. Theoretically, the CSAMT method is used to receive the E-field and the orthogonal $\mathrm{H}$-field which is produced by the magnetic field induced by transmitting the step current source into the subsurface by grounded bipole. For calculating the apparent resistivity, the Cagniard resistivity formula was employed. Finally the resistivity layers of each station will be obtained by means of matching the field apparent resistivity curve with the model one.

Because of the considerable advantages of CSAMT sounding, such as: great depth of detection, excellent lateral resolution, flexible survey design, and little topographic effect, it was applied in the Chinkuashih area to understand more of the extent of the gold-copper deposits. Based on the CSAMT sounding data in this survey, a total of three contour maps as well as three profiles were made. According to the geologic interpretation, the main factors governing the localization of the ore bodies are rock contacts, such as dacite contacts, faults, bedding planes, joints, etc. The hydrothermal solutions and sulfur which were derived from the igneous intrusions would precipitate the ore minerals. The contacts acted as channelways for magmatic water at the Chinkuashih area. This deposit model extends to the south, where concealed gold deposits might exist.
\end{abstract}

\section{INTRODUCTION}

The Chinkuashih district in northern Taiwan produced 92 tons of gold, 119101 tons of copper, and 183 tons of silver from about 20 million tons of ore from 1898 to 1987 . Ore bodies are associated spatially and genetically with the Penshan, Chiufen, and Wutanshan dacites of Pleistocene age (Figure 1 ). In the Chinkuashih area, mineralogy was studied by

1 Institute of Geophysics, National Central University, Chung-Li, Taiwan, R.O.C. 
Huang $(1964,1965)$ and Juan et al. (1959). Structural geology was investigated by Huang (1963) and Yen et al. (1979), and ore deposits were described by Huang $(1955,1960)$, Tan (1991) and Chen (1986). So, the general conditions of ore formation are known. Copper-gold mineralizations of the Chinkuashih area are associated with several late-Pliocene-Pleistocene dacite-andesite intrusions. However, the ore deposits surrounding the Chinkuashih have not been adequately accounted for. An intrusive structure which is outlined by the Wutanshan, Penshan, Tsaoshan, and Chimuling dacites has been interpreted by gravity data (Tzou,1979 ) which suggest possible concealed gold deposits. It is for this purpose the present study has been made. However, the topography is extremely rugged; most places are even impossible to reach. These make normal exploration very difficult, but pose no significant problems to a newly introduced geophysical electrical method - the Controlled Source Audiofrequency Magneotellurics ( CSAMT).

In 1992 we were asked to run a test CSAMT survey over the gravity anomaly (block region in Figure 1 ) to see if this technique would provide useful information. Based on the

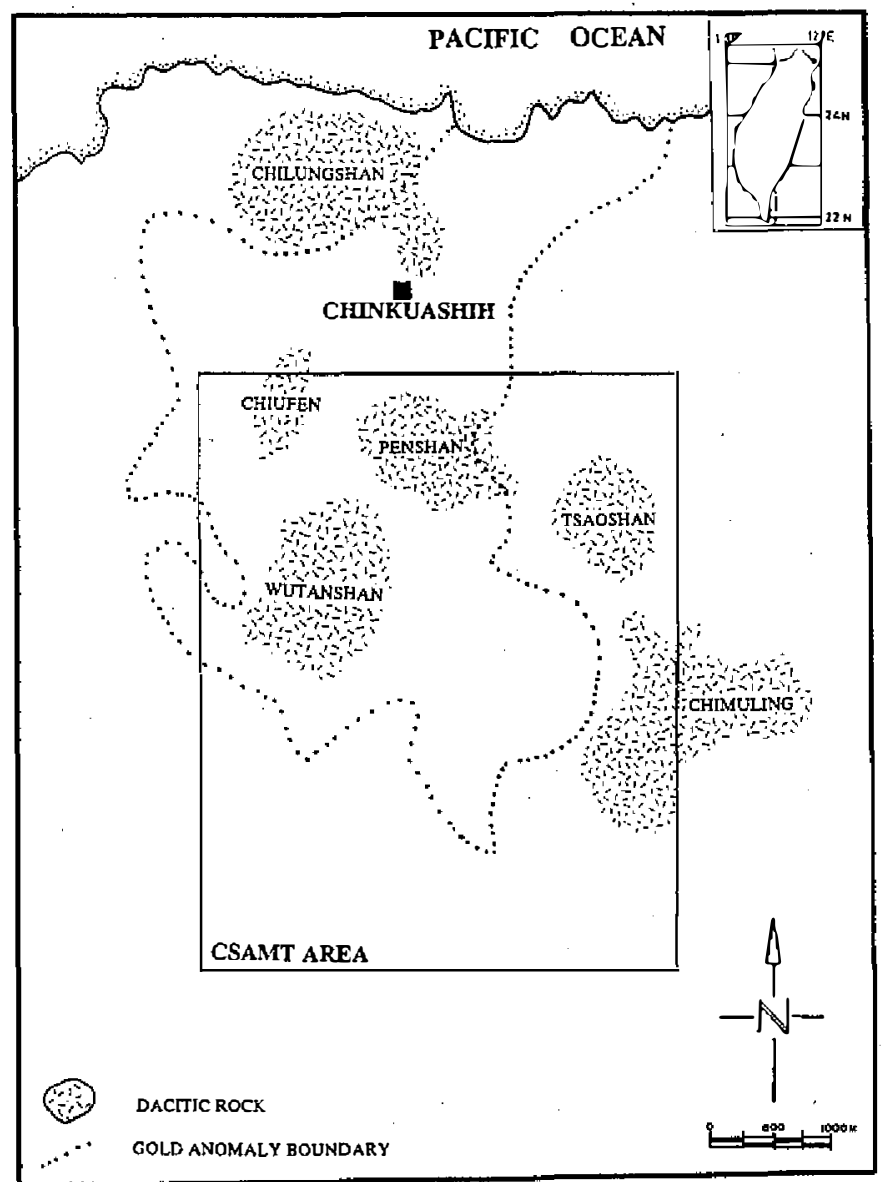

Fig. 1. The gold-copper deposits are associated spatially and genetically with the Penshan, Chiufen, and Wutanshan dacites of Pleistocene age, Chinkuashih district, northern Taiwan. The block indicates the CSAMT survey area. 
CSAMT sounding data, an intrusive beneath the survey area was confirmed, which indicates possible concealed gold deposits in the margin of this circular structure.

\section{PRINCIPLE OF THE CSAMT METHOD}

The CSAMT method, introduced by Goldstein (1971) and Goldstein and Strangway (1975), is an electromagnetic sounding technique which measures resistivity variations in the ground. Its deep penetration and high resolution make it an excellent tool for mapping silicification, hydrothermal alteration, and structural/ithological relationships associated with precious metal deposits. It is also broadly applicable to exploration for massive sulfides, uranium, base and strategic metals, geothermal and petroleum resources, and for a variety of ground contamination studies.

CSAMT measures the components of the electromagnetic field imparted to the earth by an electric bipole source (Figure 2 ). The source consists of a 1 to $4 \mathrm{~km}$ long, insulated wire, grounded at both ends by removable metal electrodes. A squarewave electric current of up to 10 amperes is injected through the bipole into the ground via a high-powered transmitter and motor generator set. The frequency of the signal is varied in order to vary the depth penetration of the survey ( the lower the frequency, the deeper the penetration). The measurements are made 2 to $4 \mathrm{~km}$ away from the source in an area where the source field approximates a plane wave.

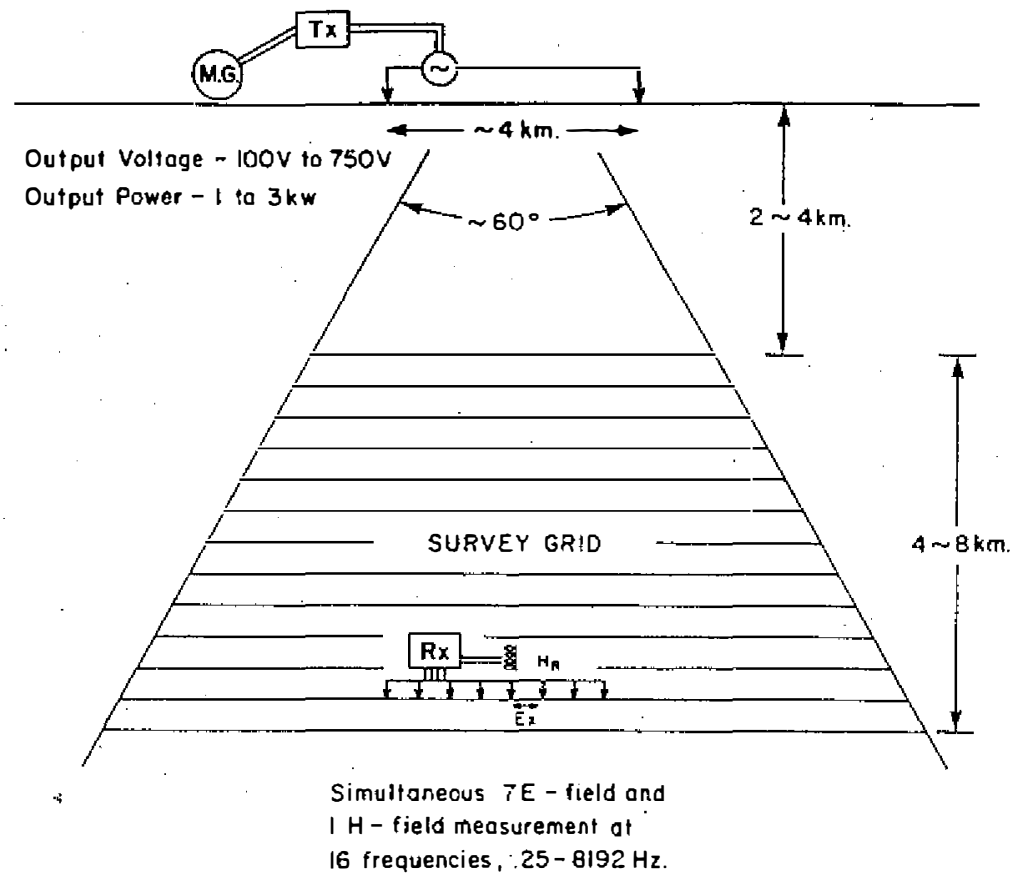

Fig. 2. Principle of the CSAMT sounding: CSAMT measures the electric (E) and magnetic $(\mathrm{H})$ components of the electromagnetic field imparted to the earth by a remote electric bipole source (After PHOENIX GEOPHYSICS LIMITED). 
CSAMT measures the electric $(\mathrm{E})$ and magnetic $(\mathrm{H})$ components of the electromagnetic field. The E-field is sensed as a voltage across a grounded wire, while the $\mathrm{H}$-field is sensed as a voltage in a high-gain magnetic antenna. The ratio of perpendicular components of $E$ and $H$ gives the Cagniard resistivity ( Cagniard, 1953 ) of the ground:

$$
\text { Cagniar resistivity } R=(E / H)^{* *} 2 /(5 f)(R \text { in ohm- meters) }
$$

Their phases yield another quantity known as phase difference or impedance phase:

$$
\text { Impedance phase } \mathbf{P}=\mathrm{E} \text {-phase }-\mathrm{H} \text {-phase ( } \mathrm{P} \text { in milliradians) }
$$

The depth of CSAMT data is related to signal frequency $f$ and to resistivity $R$ :

$$
\text { Depth } \mathrm{D}=356^{*}\left(\mathrm{R} / \mathrm{f}^{* *} 0.5 \text { ( } \mathrm{D}\right. \text { in meters). }
$$

CSAMT surveys generally take data in the range of 0.125 to $8192 \mathrm{~Hz}$. Thus, in typical mining environments, penetration down to 2 or $3 \mathrm{~km}$ is easily achievable. Lateral resolution is controlled by the E-field dipole size. Thus, CSAMT can use a very small electric field dipole to achieve high lateral resolution while still getting deep penetration by using low frequencies.

It is worth noting that CSAMT measurements are made far from the source, in the farfield zone. Therefore the sounding path is directed vertically into the ground, and penetration depends upon ground resistivity and signal frequency, not receiver-transmitter separation. So, CSAMT has inherently less topographic effect than traditional geometric sounding methods.

However, the disadvantage of the CSAMT method is the nearness of the signal source. The plane wave assumption which simplifies both the mathematics of the technique and the interpretation of data is no longer true where the receiver is close to the transmitter; under such circumstances the calculated apparent resistivity must be corrected for the near-field effect ( Goldstein and Strangway, 1975 ).

\section{DATA ACQUISITION AND PROCESSING}

For delineating the Chinkuashih area and its surrounding area, a detailed CSAMT survey along four profiles which are parallel to the transmitter bipole $(3 \mathrm{~km} \times 2 \mathrm{~A})$ has been carried out (Figure 3). Instruments of CSAMT, IPT1 transmitter and V4 receiver (PHOENIX GEOPHYSICS LIMITED) with a capability of measuring the response in a frequency range of 0.25 to $8192 \mathrm{~Hz}$ with a binary step, were used. The standard configuration performs six E-field and one H-field measurement at each of 16 frequencies $(0.25$ to $8192 \mathrm{~Hz})$. The E-fields are measured with a dipole using steel electrodes. The survey traverse is of equally spaced E-dipoles, and each dipole length fixes at 100 meters. A horizontal magnetic sensor coil (AMT-25) is placed on the ground, approximately at the center of the series of E- dipoles. It must be placed several meters away from the E-dipole line and the receiver console, to avoid interference, as well as to reduce inductive coupling due to operator movement. Only one $\mathrm{H}$-field measurement is required for each group of six E-field measurements as field experiences indicated that the lateral variation of apparent resistivity is dominated by the lateral variation of the E-field, while the lateral variation of the H-field is very small. More than sixty soundings were conducted in this area. 


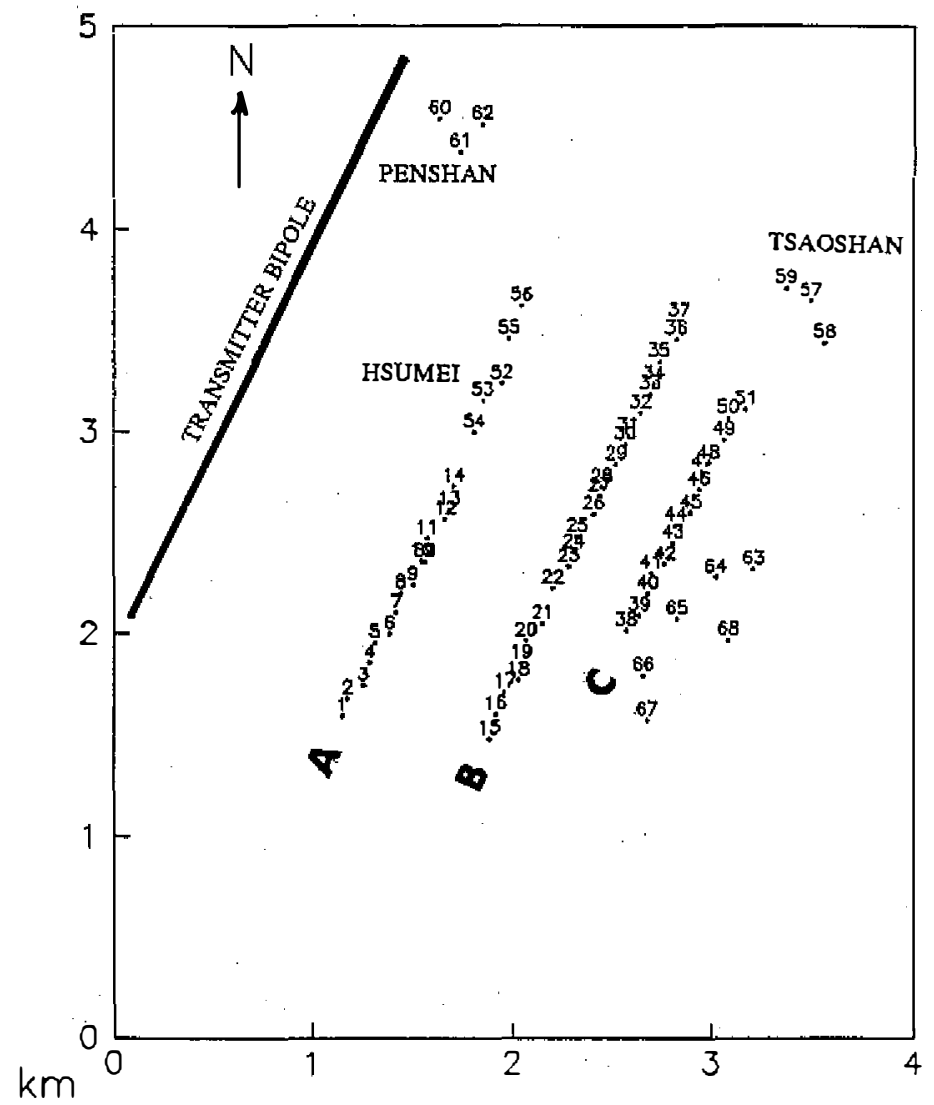

Fig. 3. The CSAMT sounding locations (no. 1-67) and three profiles (A, B and C) in the Chinkuashih area. The bold line indicates the transmitter bipole.

Each measurement was recorded by stacking up to 20 readings before being saved . To aid in qualitative interpretation and inversion, values of apparent resistivity were computed. Apparent resistivity is the resistivity of a homogeneous earth which would produce the measured response at a single frequency.

All of the CSAMT soundings were then 'inverted ' by computer curve fitting for quantitative interpretation. This progran used the basic adaptive nonlinear least-squares algorithm. Good results fit all field data by using three to four layer models. Some of the typical field data and their inverted results were shown in Figure 4. Consequently, without having other geophysical or geologic information strongly suggesting other suitable models, we used these inverted models for interpretation.

\section{RESULTS}

We employed the frequency slice maps (Figure 5) to display the qualitative results, the three profile maps ( Figure 6, Figure 7, and Figure 8) to interpret quantitatively, and the depth slice maps (Figure 9) to estimate the 3-D structures in the survey area. 


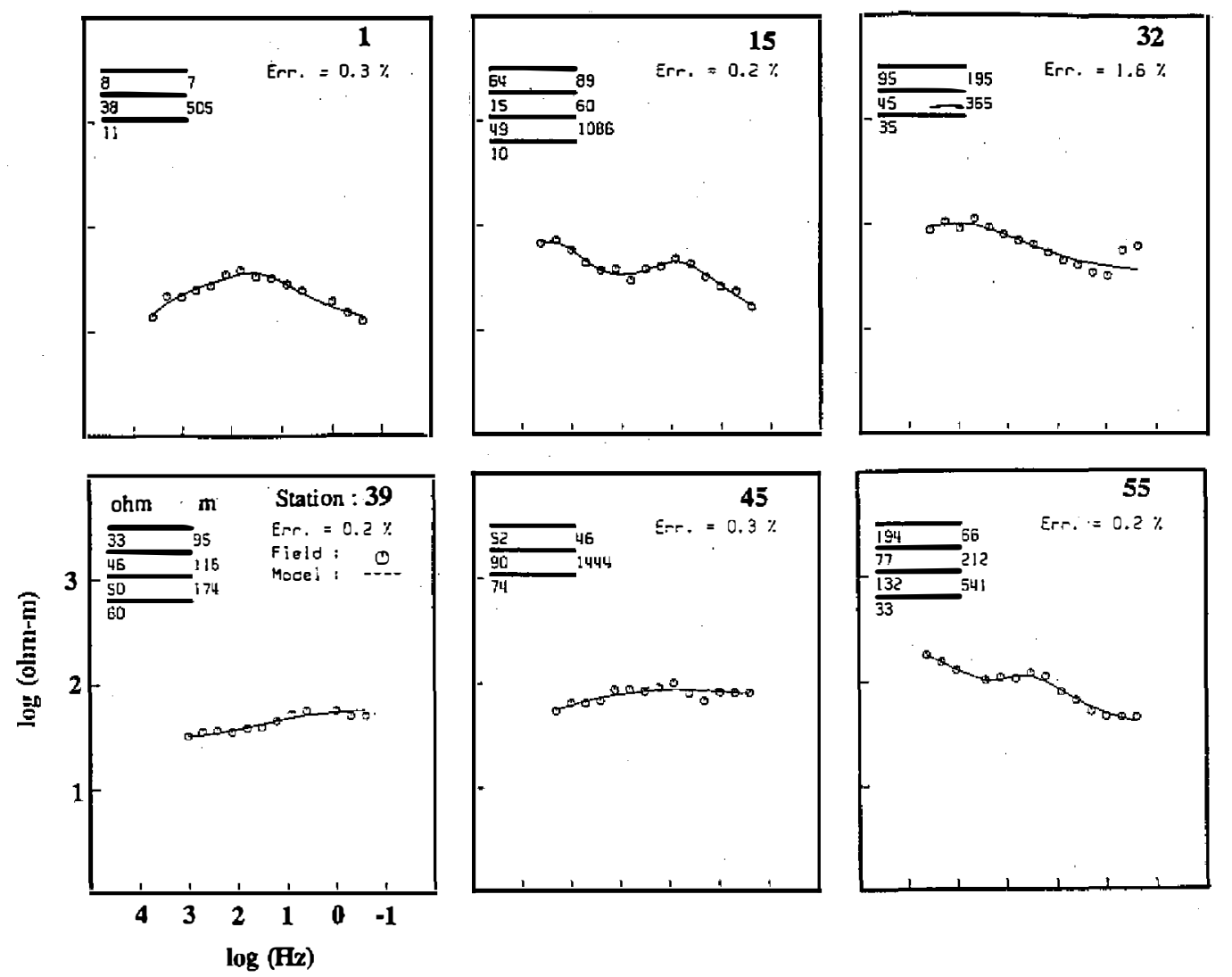

Fig. 4. Some typical field data and the inverted results of the CSAMT soundings in the Chinkuashih area, northern Taiwan. Good result fits to all of the field data by using three to four layer models.

\subsection{Frequency Slices}

To assess the subsurface structure qualitatively, three apparent resistivity contour maps with selected frequency equal to 2050,512 , and $0.5 \mathrm{~Hz}$ respectively were drawn. Figure 5 depicts the final results along with the known geology also drawn on a contour map to facilitate comparisons. The $2050 \mathrm{~Hz}$ frequency corresponds to the top 100 meters, while the $0.5 \mathrm{~Hz}$ data penetr ates more than $1 \mathrm{~km}$, depending upon local resistivity.

The shallower CSAMT data (Figure 5a ) show a strong electrical resistor being observed directly over the northem silicified zone (Penshan and Tsaoshan ). This resistor is closely contacted by conductive zones to the south, which are thought to be conductive clay alteration surrounding the silicification. In the southern conductive zone a dike-like resistive zone was detected beneath around stations 21 and 7 . This resistive feature was the discovered silicified structure that would be of interest from a gold exploration standpoint.

The deeper CSAMT data (Figure $4 \mathrm{~b}$ and $4 \mathrm{c}$ ) show the same geoelectric patterns, but generally more conductive material, which is not surprising due to the pervasive fluids which 
(a) $2050 \mathrm{~Hz}$

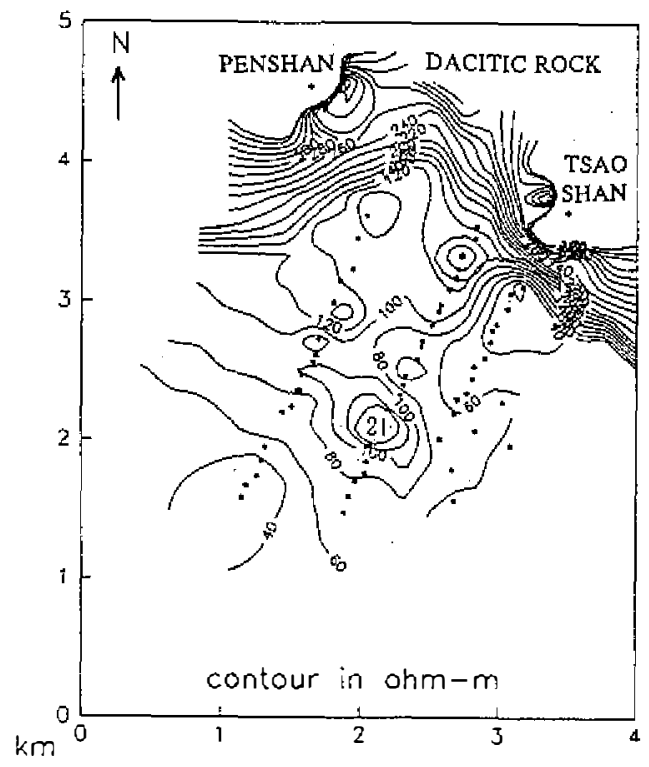

(b) $512 \mathrm{~Hz}$

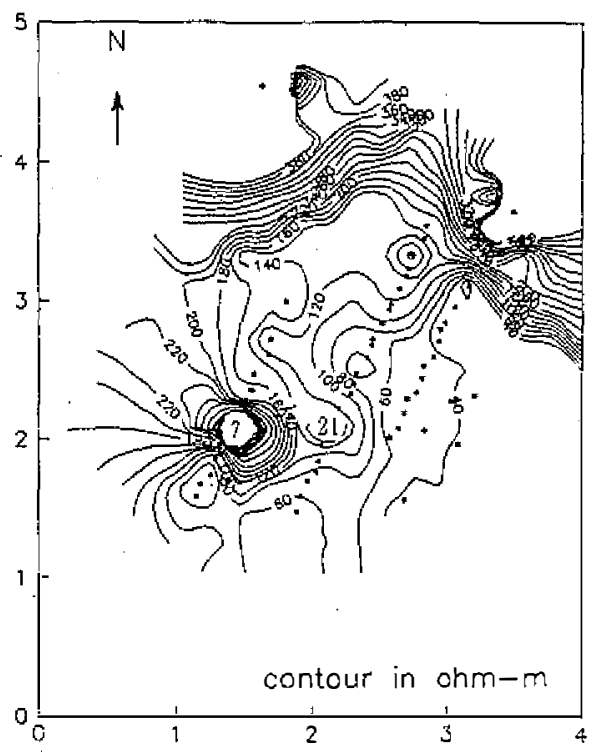

(c) $0.5 \mathrm{~Hz}$

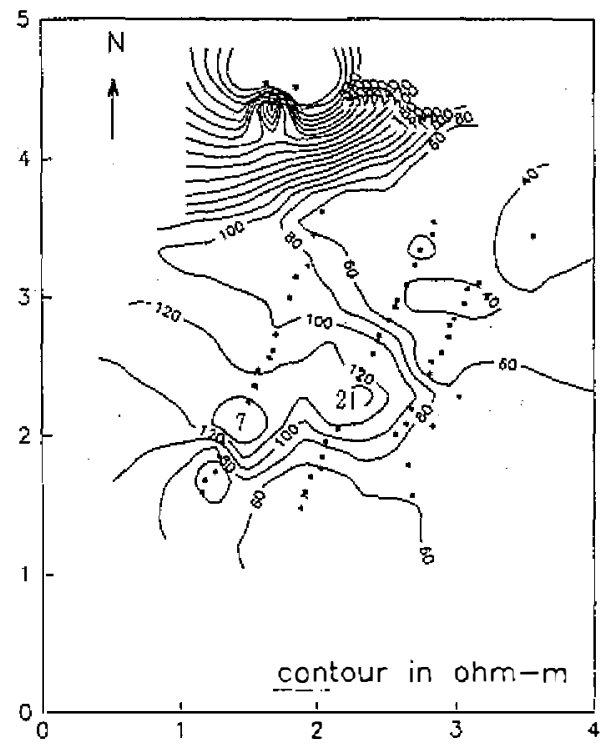

Fig. 5. Apparent resistivity contour maps of frequencies (a) $2050 \mathrm{~Hz}$, (b) 512 $\mathrm{Hz}$, and (c) $0.5 \mathrm{~Hz}$ respectively in the Chinkuashih area. Dots on each map indicate the sounding points. Contours are in ohm-m. Note that each frequency slice has the high resistivity anomalies around station 7 and 21 which are the discovered intrusives. 
are found in the area. In order to interpret the subsurface structure quantitatively, three profiles were prepared, from the inversion results of the CSAMT data, as follows:

\subsection{Profile A}

A $2.2 \mathrm{~km}$ long line trending SW was surveyed. Figure 6 illustrates the results of CSAMT sounding on this profile. The triangles indicate the sounding points. The interpreted positions of the layers and their resistivities in ohm-m are also shown in this figure. The depth detected by CSAMT is more than $1.5 \mathrm{~km}$.

As this profile is across the known outcrop of the Hsumei gold- copper deposit which is located between sounding no. 53 and 52 , interpretations of this profile could be correlated with this known geology. The resistive zone is observed to the SW of the Hsumei mine, while the conductive zone is observed to the NE. These signatures are thought to be conductive clay alteration surrounding the resistive silification. CSAMT data also indicates the Hsumei deposit extends deeper than $1 \mathrm{~km}$, which was not previously known.

Other than the structure of the Hsumei deposit, a resistivity discontinuity is clearly. visible between stations 3 and 5 . This fault separates altered (conductive) rocks to the SW from fresh (resistive) silification to the $\mathrm{NE}$.

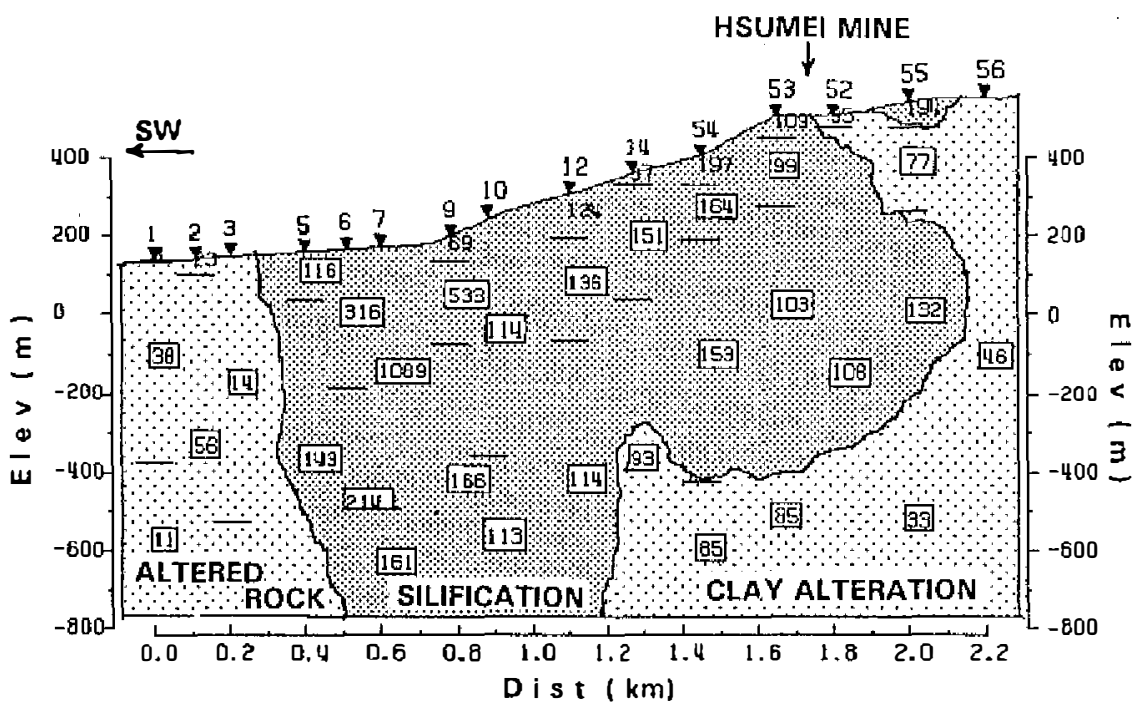

Fig. 6. Geoelectric sectin of profile A in Figure 3 and its geologic interpretations. The triangles indicate the sounding points. The interpreted positions of the layers and their resistivities in ohm-m are also shown in this figure.

\subsection{Profile B}

This $2.2 \mathrm{~km}$-long SW-trending profile (Figure 7) is the key profile to realize the mineral conditions as it runs through the center of the survey area. Figure 7 shows the interpreted section derived from CSAMT sounding data. Compared with profile B and A, one can see 
that the prominent features of profile B are the southern extension of profile A. Two conductive areas appear to flank the dike-like resistive feature located between stations 21 and 28 . Either of the conductive features could represent alteration of silicate minerals to clays. The NE conductive zone could be correlated with the known Hsumei mines in profile A, however, the $S W$ conductive zone still needs drilling to confirm it.

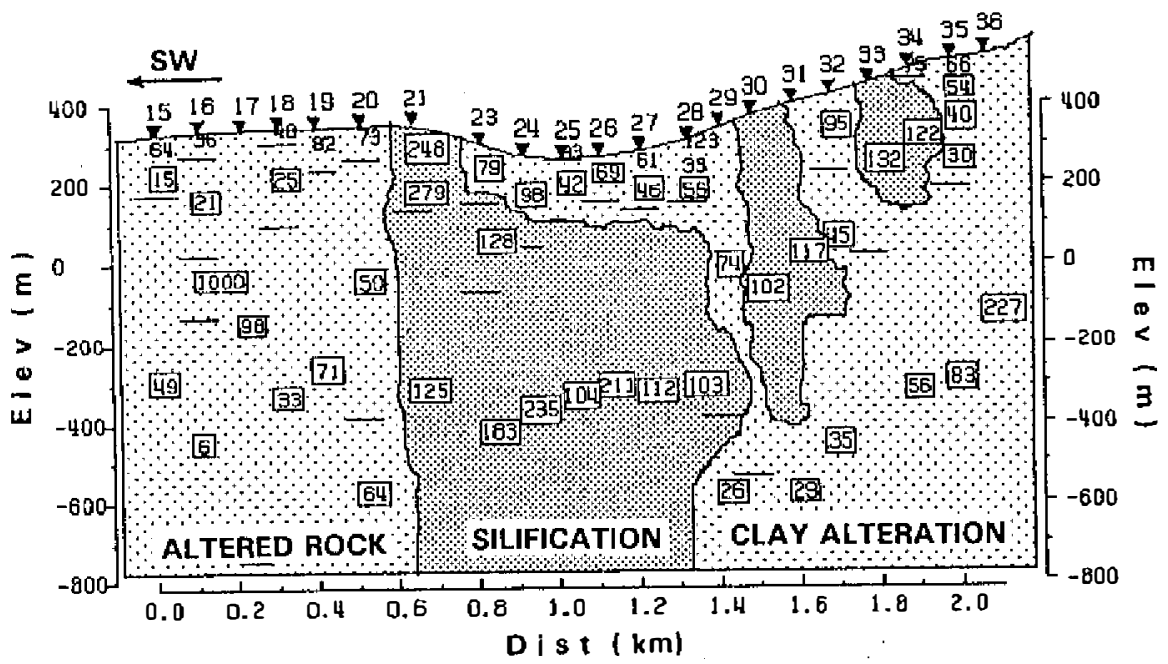

Fig. 7. Geoelectric section of profile B in Figure 3 and its geologic interpretations.

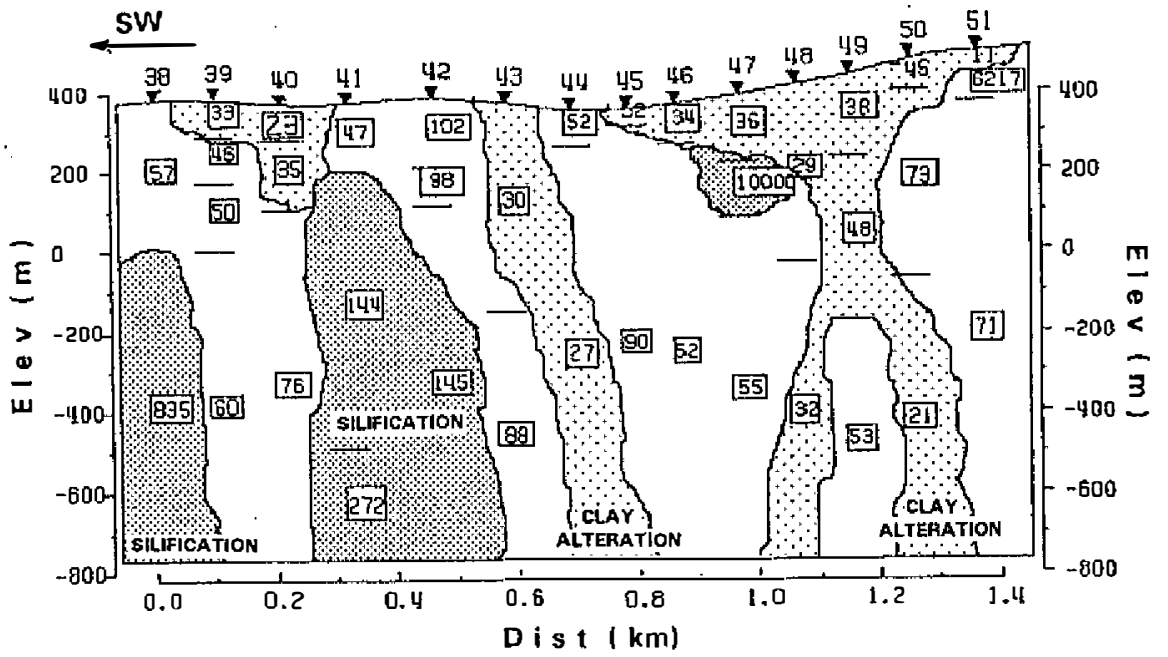

Fig. 8. Geoelectric section of profile $\mathrm{C}$ in Figure 3 and its geologic interpretations. 


\subsection{Profile C}

A $1.2 \mathrm{~km}$ long line, termed profile C, also trending SW, was surveyed. Figure 8 shows the results of CSAMT sounding on the profile. The inverting resistivity along the line has several prominent features. A deep strong resistive zone can be seen beneath station 38 and a resistive dike-like zone is centered beneath station 41 . A broad conductive area appears to flank the dike-like feature. Either of the resistive features could represent silicified structure that would be of interest from a gold exploration standpoint.

Comparing profile $\mathrm{C}$ and profile $\mathrm{B}$, features of profile $\mathrm{C}$ could be generally correlated with profile $B$, indicating the Chinkuashih mine has extended to the south, but seems to be diminished.

\subsection{Depth Slices}

Based on the above 3 resistivity profiles, resistivity contour maps at depth $200 \mathrm{~m}$, $500 \mathrm{~m}$, and $1000 \mathrm{~m}$ were made (Figure 9) for interpreting the possible 3-D distribution of the gold-copper deposit in the Chinkuashih area. The known outcrop of the Hsumei goldcopper deposit is also drawn on each slice map to facilitate comparisons. The resistive zone is observed to the SW of the Hsumei mine, while the conductive zone is observed to the NE. These signatures are though to be conductive clay alteration surrounding the resistive silification. These depth slices can be used to estimate the direction and extent of the the Chinkuashih deposit in 3-D distribution in this area. The Chinkuashih deposit is believed to be, from CSAMT view point, extended to the south of the Chinkuashih area where there might be concealed gold deposits.

\section{CONCLUSIONS}

Based on the results of the CSAMT soundings carried out in the Chinkuashih area, goldcopper deposits occur in insufficient quantities to be directly detected by CSAMT. Hence, interpretations have been concentrated upon identifying geologic conditions where gold-copper deposits are likely to be found. Fortunately, many of these geologic circumstances have distinct electrical signatures which can be measured by CSAMT techniques. For example, clay alteration is often conductive, silicification resistive, contact boundary conductive, etc.

According to the survey results at Hsumei outcrop ( profile A ), the main factor goveming the localization of the ore bodies are rock contacts, such as dacite contacts, faults, bedding planes, joints, etc. The hydrothermal solutions and sulfur which were derived from the igneous intrusions would precipitate the ore minerals. The contacts acted as channelways for magmatic water at the Chinkuashih area. This deposit model extends to the south of the Chinkuashih area where there might be concealed gold deposits.

The results presented in the paper do show the potential of CSAMT sounding methods to be more useful for deep geologic mapping, especially for the detection of lateral boundaries, such as faults and folds, where no detailed geological information is available, either because the bedrock geology is concealed by overburden or drillhole surveys have not yet begun. Such techniques will be important in mountainous regions near an earthquake belt. 
(a) $200 \mathrm{~m}$

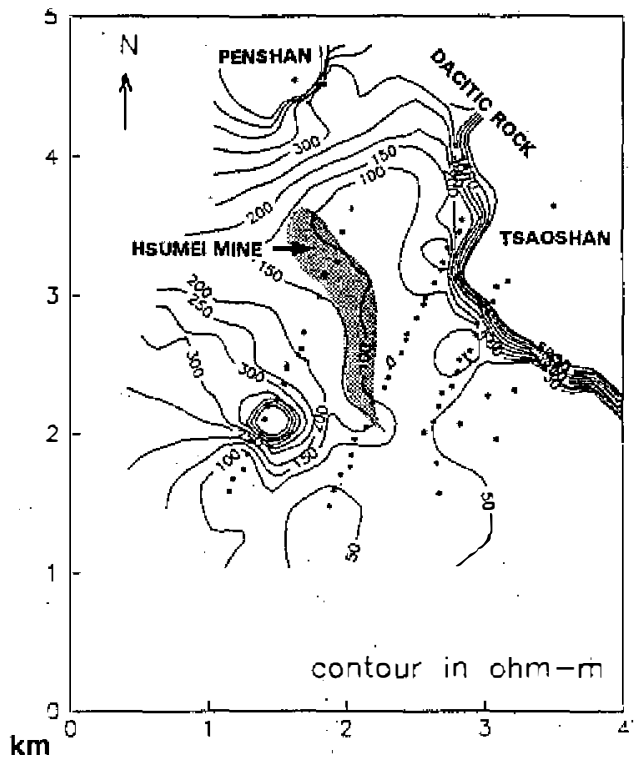

(b) $500 \mathrm{~m}$

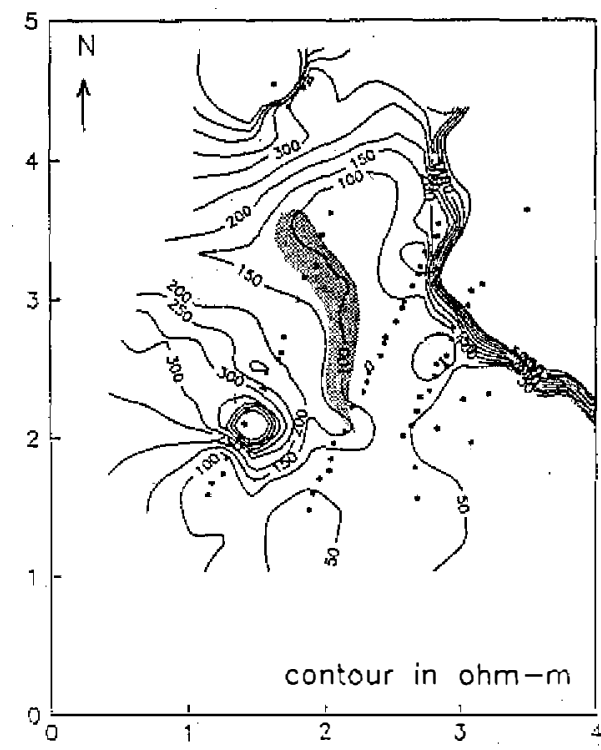

(c) $1000 \mathrm{~m}$

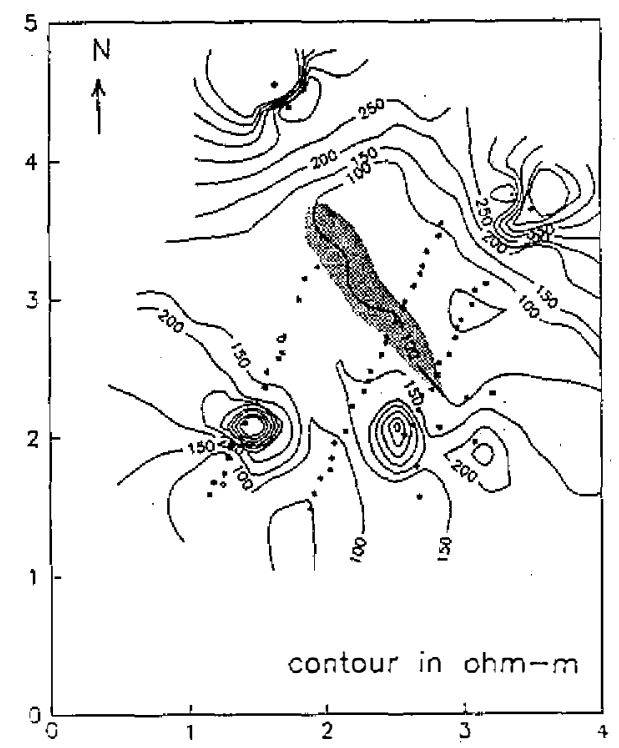

Fig. 9. The resistivity contour maps of depths (a) $200 \mathrm{~m}$, (b) $500 \mathrm{~m}$, and (c) 1000 $\mathrm{m}$ respectively in the Chinkuashih area. Contours are in ohm- $\mathrm{m}$. The resistive zone is observed to the SW of the Hsumei mine, while the conductive zone is observed to the NW. These signatures are though to be conductive clay alteration surrounding the resistive silification. CSAMT results indicate the Hsurnei deposit extends to the south of the Chinkuashih area, which was not previously known. 
Acknowledgements The research described in this paper has been funded by the Energy and Resources Laboratories, ITRI. The research assistants Messrs. F. S. Tseng and D. S. Chen participated in the field surveys . I appreciate their contributions to the data collection. Further thanks are due to the project manager Mr. C. C. Chang, my teacher Dr. T. P. Yen and colleague C. Y. Wang for their valuable information, support, and discussion.

\section{REFERENCES}

Cagniard, L., 1953: Basic theory of the magnetotelluric method of geophysical prospecting. Geophysics, 18, 605-635.

Chen, C. C., 1986: Copper and gold mineralizations in the Chinkuashih area, northem Taiwan. Proc. Geol. Soc. China, 29, 63-71.

Goldstein, M. A., 1971: Magnetotelluric experiments employing an artificial dipole source. Ph. D. Thesis, Depart. Physics, Univ. Toronto.

Glodstein, M. A., and D. W. Strangway, 1975: Audio frequency magnetotelluric with a grourided dipole source. Geophysics, 40, 669-683.

Huang, C. K., 1955: Gold-copper deposits of the Chinkuashih mine, Taiwan. Acta Geol. Taiwanica, 7, 1-20.

Huang, C. K., 1960: Gold deposits of the Wutanshan area, Taiwan. Acta Geol. Taiwanica, 8, 13-25.

Huang, C. K., 1963: Factors controlling the gold-copper deposits of the Chinkuashih mine, Taiwan. Acta Geol. Taiwanica, 10, 1-9.

Huang, C. K., 1964: Mineralogy of the Tsaoshan deposits of Chinkuashih mine. Proc. Geol. Soc. China, 7, 1-39.

Huang, C. K., 1965: Future notes on the mineralogy of the Chinkuashih gold-copper deposits, Taiwan. Acta Geol. Taiwanica, 11, 31-43.

Juan, V. C., Y. Wang, and S. S. Sun, 1959: Hydrothermal alteration of dacite at the Chinkuashih mine, Taipeihsien, Taiwan. Proc. Geol. Soc. China, 2, 73-92.

Tan, L. P., 1991: The Chinkuashih gold-copper deposits, Taiwan. Soc. Economic Geololgists News Let ter, 7, 21-24.

Tzou, Y. H., 1979: Gravity pattern in Chilung volcano group, northem Taiwan. Bull. Geophysics, 18, 25-33.

Yen, T. P., Y. H. Tzou, and S. W. Wu, 1979: Geology of the Chilung volcano group district, northem Taiwan. Proc. Geol. Soc. China, 22, 94-104. 